\title{
The Formation of Saw Toothed Chip in a Titanium Alloy: Influence of Constitutive Models
}

\author{
Roberto Alvarez ${ }^{1}$ - Rosario Domingo ${ }^{2, *}$ - Miguel Angel Sebastian ${ }^{2}$ \\ 1 Universidad Nebrija, Department of Industrial Engineering, Spain \\ 2 UNED, Department of Manufacturing Engineering, Spain
}

This work analyses the effect of eight constitutive models on the saw-toothed chip formation in Ti6Al4V orthogonal cutting, by means of the finite element (FE) simulation and experimental contrast, in dry and with conventional emulsion coolant, mixed with water at 7\%. The models are focused in JohnsonCook equations with four different sets of constant parameters, El-Magd-Treppmann modified and three Zerilli-Armstrong models based on the behavior of different crystal structures (body-centered-cubic BCC, hexagonal-close-packed-HCP and modified HPC model). The flow stress model of Ti6Al4V at high strain rates and temperatures has been analysed using a 2-D FE model through constitutive equations and three friction coefficients (0.4, 0.6 and 0.8). A critical comparison of outstanding process outputs as cutting force, temperature - on rake face and measurable parameters for segmented chip (the peak tooth height, the valley tooth height and the tooth width, chip compression ratio, and chip deformation) is carried out. The application of different constitutive models has proved a strong influence on the results. Zerilli-Armstrong models, for BCC and HCP structures, have achieved the best fitting in machining with and without coolant respectively, for a friction coefficient of 0.8 , getting for cutting force, temperatures, peak tooth height and chip deformation, deviation lower than $2 \%$. The chip compression ratio has reached $4.7 \%$ and $7 \%$ for BCC and HCP respectively. Only the valley tooth height and the tooth width show some limitations.

(C)2011 Journal of Mechanical Engineering. All rights reserved.

Keywords: machining, orthogonal cutting, Ti6AI4V, FEM, chip morphology, constitutive models

\section{INTRODUCTION}

Ti6Al4V has become one of the basic materials in aerospace, armour and medical device industry due to its mechanical resistance, tenacity, low density and exceptional corrosion resistance. However, this material is difficult to machine due to its low thermal conductivity that decreases with higher temperatures, a characteristic called thermal softening. Moreover, during the process, this alloy reaches high strains, very high strain rates and temperatures close to its melting point. In addition, it is remarkable that Ti6Al4V possesses a phase transformation. Initially, an alpha phase with a Hexagonal-Close-Packed (HCP) crystal structure is presented, and it changes to a beta phase with a Body-Centered-Cubic (BCC) crystal structure, approximately at $996^{\circ} \mathrm{C}$. The properties of the materials, the thermo-mechanical flow and the chip fracture, involved in machining processes, are essential inputs for the definition of a finite element (FE) model. The constitutive equation model and the set of parameters selected for the flow behavior of workpiece material could influence the saw-toothed chip morphology. Thus, specific flow stress expressions have been proposed to approach the flow stress behavior in metal cutting. Simulations by the FE model, based on Johnson-Cook (J-C) equations, related to orthogonal cutting, focused on an analysis of influence of Ti6Al4V proprieties and found that there is a critical point - phase transformation at which the chip loses the property of continuous [1]. The chip segmentation was analyzed by means of a model based on a simple isotropic von Mises flow stress law - it is a modification of El-Magd and Treppmann constitutive model, allows an observation of the variation of thermal conductivity affecting the segmentation [2]. The development of a model based on J-C equations that takes into account the strain rate hardening, the thermal-softening phenomenon and the strainsoftening phenomenon, has found that the election of material law is primordial to the machining

*Corr. Author's Address: UNED University,

C/ Juan del Rosal 12, Madrid, Spain, rdomingo@ind.uned.es 
simulation and that at high cutting speeds it is difficult to predict the segmented chip [3]. An analysis of the cutting force, chip morphology and segmentation through the J-C's constitutive equation with three different sets of material constants reports that a good prediction of cutting force and chip morphology can be achieved only if the material constants were identified using experimental data [4]. The influence on serrated chip formation, of three material models based on $\mathrm{J}-\mathrm{C}$ equations, has been researched and it has been found that the serrated chip does not get in in its entirety and that the chip geometry in FE depends on model equation, However, it does not depend on the cutting conditions [5]. The exploration of the FE modeling use by a J-C model (although it does not report the data of constitutive equations) in a study of the chip curl, allows an observation of a reasonable agreement with a small depth of cut [6]. Also, a procedure has been defined to determine values of friction and damage coefficients to find a serrated chip [7]. A model whose constitutive equation represents the $\mathrm{BCC}$ structure called the Zerilli-Armstrong model in order to identify parameters for high rate metal cutting conditions has been found [8], but its adequacy to $\mathrm{FE}$ simulation has not been verified.

Although, the J-C model is probably the most used constitutive equation and its combination with a ductile fracture criterion has been used to simulate chip formation in machining Ti6Al4V, the equation could be considered inappropriate for the Ti6Al4V alloy, as it does not incorporate the characteristic nonlinear strength behavior shown by the material. Thus, variations of the $\mathrm{J}-\mathrm{C}$ primitive equation have been proposed. On the other hand, there are other models which have been less explored, such as the Bäker modification and specially Zerilli-Armstrong model. Moreover, the equation constitutive for HCP structure is not proved. This study focuses on eight constitutive models for the thermo-viscoplastic flow behavior of workpiece material in orthogonal cutting, with three friction coefficients and an experimental contrast, statistically verified, with and without coolant. The introduction of dry or flooded machining is a new and important consideration since differences between the performances in dry and flooded machining have been found in an experimental research focussed on biomedical applications of titanium [9]. Therefore, the contributions of this paper are the following: i) to explore the capacity of Zerilli-Armstrong models in FE simulations; ii) to integrate the Zerilli-Armstrong models, the Baker modification of El-Magd and Treppmann and a J-C model with a lower thermal softening coefficient (than others contrasted in the literature) with the fracture criterion; and iii) to find the influence of lubrication on the results and the effect of the friction coefficient in dry and flooded cutting conditions in the eight models.

\section{MATERIAL MODELS AND EQUATIONS}

In order to express the complex flow behavior of Ti6Al4V alloy, which depends on the local strain, strain rate and temperature, a proposed 2-D orthogonal cutting FE model is used. The cutting conditions and material properties of the workpiece will be the inputs of the simulation process, while the outputs will be variables of the process as chip morphology, cutting force and temperature. The flow is studied by the models described in this Section.

\subsection{Johnson and Cook Constitutive Model}

The J-C equation is a multiplicative phenomenological strength model, Eq. (1). Three factors describe the flow stress considering the material strain and strain rate as well as the thermal influence respectively [10]:

$$
\sigma=\left[A+B \cdot \varepsilon^{n}\right] \cdot\left[1+C \cdot \ln \left(\frac{\dot{\varepsilon}}{\dot{\varepsilon_{0}}}\right)\right]\left[1-\left(\frac{T-T_{r}}{T_{m}-T_{r}}\right)^{m}\right]
$$

where $\sigma$ is the equivalent flow stress [MPa], $\varepsilon$ the equivalent plastic strain, $\dot{\varepsilon}$ and $\dot{\varepsilon}_{0}$ the equivalent plastic strain rate $\left[\mathrm{s}^{-1}\right]$ and the reference equivalent plastic strain $\left[\mathrm{s}^{-1}\right], T$ the workpiece temperature and $T_{m}$ and $T_{r}$ are, respectively, the material melting and room temperatures. The coefficient $A$ [MPa] is the yield strength; $B[\mathrm{MPa}]$ the hardening modulus; $C$ the strain rate sensitivity coefficient; $n$ the hardening coefficient; $m$ is the thermal softening coefficient. $A, B, C, n$ and $m$ are constant values. Table 1 shows a different set of parameters proposed [11] to [14] and tested in this paper. The 
constants used in the models E1, E2 and E4 were identified through the Split Hopkinson Pressure Bar (SHPB) method, which was applied at a maximum strain rate of $2150 \mathrm{~s}^{-1}$ and a maximum plastic strain of 0.57 . The constants for the $\mathbf{E 3}$ model were studied with a methodology based on analytical modelling of the orthogonal cutting process combined with metal cutting experiments [13]. It must be said that there is no information about the range of strain rate and true strain. The three first models tested [4] are used as a pattern for this work joint to the experimental verification.

\subsection{Bäker Modification of El-Magd Constitutive Model}

El-Magd and Treppmann [15] determined a flow stress law for the alloy Ti6Al4V, which was modified by Bäker [2]. In this constitutive model (E5), the plastic behavior is described by an isotropic equation based on Von Mises flow stress law. It is given by the Eq. (2), where $C$ is a constant and $K^{*}[\mathrm{MPa}], n^{*}, \mu$ and $T_{M T}[\mathrm{~K}]$ are parameters calculated from experimental data through quasi-static compression tests and SHPB method (see Table 2). The appropriate range of values is strain rates between $10^{3}$ and $10^{4} \mathrm{~s}^{-1}$ for a temperature value of $400{ }^{\circ} \mathrm{C}$.

$$
\sigma=K^{*} \cdot e^{\left(-\left(\frac{T}{T_{M T}}\right)^{\mu}\right) \varepsilon^{n^{*} \exp \left(-\left(\frac{T}{T_{M T}}\right)^{\mu}\right.}} \cdot\left(1+C \ln \left(\begin{array}{c}
\dot{\varepsilon} \\
\hline \dot{\varepsilon_{O}}
\end{array}\right)\right)
$$

\subsection{Zerilli and Armstrong BCC Constitutive Model}

Zerilli and Armstrong constitutive model is based on dislocation mechanics. Its development pursues to represent the behavior of BCC structure metals, which is given in Eq. (3) [16]. This structure is typical in Ti6A14V at temperatures above $996{ }^{\circ} \mathrm{C}$. It presents some advantages regarding the $\mathrm{J}-\mathrm{C}$ model because it better describes the strain rate hardening behavior and the thermal coupling [12]. The E6 model represents the BCC structure and the parameters for the material constants $C_{0}[\mathrm{MPa}], C_{1}[\mathrm{MPa}]$, $C_{3}\left[\mathrm{~K}^{-1}\right], C_{4}\left[\mathrm{~K}^{-1}\right], C_{5}[\mathrm{MPa}]$ and $n$ are taken from Meyer and Kleponis [12] research of a low cost Ti6Al4V for strain rates up to $2,000 \mathrm{~s}^{-1}$. The strain rate and the temperature are independent of strain effects. The parameters have been selected by means of numerical simulations, choosing the values that provide the best fitting.

$$
\sigma=C_{0}+C_{1} \cdot e^{\left(-C_{3} \cdot T+C_{4} \cdot T \cdot \ln \dot{\varepsilon}\right)}+C_{5} \cdot \varepsilon^{n} .
$$

\subsection{Zerilli and Armstrong HCP Constitutive Model}

Later on, Zerilli and Armstrong expanded the applicability of the BCC model developing a better understanding representation for metals [17] predominantly HCP structure (E7). This model is relevant in the machining because HCP is the crystal structure of Ti6Al4V until $996^{\circ} \mathrm{C}$. Its development pursues to improve the representation of the thermal softening phenomenon. Eq. (4) represents this HCP model E7. Parameters $C_{0}$ [MPa], $C_{1}[\mathrm{MPa}]$ and $C_{2}[\mathrm{MPa}]$ are material constants and $T$ is the absolute temperature. The expression under the radical is known as strain function. The recovery strain $\varepsilon_{r}$ affects the strain $\varepsilon$, at which the saturation of the stress is achieved. The parameters $\alpha_{0}\left[\mathrm{~K}^{-1}\right], \beta_{0}\left[\mathrm{~K}^{-1}\right], \dot{\varepsilon}_{\alpha}\left[\mathrm{s}^{-1}\right]$ and $\dot{\varepsilon}_{\beta}$ $\left[\mathrm{s}^{-1}\right]$ are material constants [18]. The parameters have been determined in the same manner as the values for Eq. (3).

$\sigma=C_{0}+C_{1} \cdot \varepsilon^{\left.-\beta_{0} \cdot 1-\frac{\ln \dot{\varepsilon}}{\ln \dot{\varepsilon}_{\beta}}\right]}+C_{2} \cdot e^{-\alpha_{0} \cdot 1-\left[-\frac{\ln \dot{\varepsilon}}{\ln \dot{\varepsilon}_{\alpha}}\right]} \cdot T \cdot \sqrt{\varepsilon_{r} \cdot\left(1-e^{-\varepsilon / \varepsilon_{r}}\right)}$

Table 1. Parameters of $J$-C models $\sigma$ in [MPa]

\begin{tabular}{|c|c|c|c|c|}
\hline & E1 [11] & $\mathbf{E 2 ~ [ 1 2 ] ~}$ & $\mathbf{E 3}[13]$ & $\mathbf{E 4}[14]$ \\
\hline$A[\mathrm{MPa}]$ & 782.7 & 896 & 870 & 862.5 \\
\hline$B[\mathrm{MPa}]$ & 498.4 & 656 & 990 & 331.2 \\
\hline$C[-]$ & 0.028 & 0.0128 & 0.008 & 0.012 \\
\hline$n[-]$ & 0.28 & 0.5 & 1.01 & 0.34 \\
\hline$m[-]$ & 1 & 1 & 1.4 & 0.8 \\
\hline$\cdot \dot{\boldsymbol{\varepsilon}}_{o}\left[\mathrm{~s}^{-1}\right]$ & $10^{-5}$ & 1 & 1 & 1 \\
\hline$T_{m}\left[{ }^{\circ} \mathrm{C}\right]$ & 1600 & 1600 & 1600 & 1600 \\
\hline
\end{tabular}


Table 2. Parameters of $\boldsymbol{E} 5$ model $\sigma$ in [MPa] [2]

\begin{tabular}{|c|c|c|c|c|c|}
\hline$C[-]$ & $\dot{\varepsilon_{o}}$ & $K^{*}$ & $n^{*}$ & $T_{M T}$ & $\mu$ \\
{$[\mathrm{MPa}]$} & {$[-]$} & {$[\mathrm{K}]$} & $\begin{array}{c}\mu \\
{[-]}\end{array}$ \\
\hline 0.302 & 774 & 2260 & 0.339 & 825 & 2 \\
\hline
\end{tabular}

\subsection{Zerilli and Armstrong HCP Modified Constitutive Model}

The model proposed by Zerilli and Armstrong with predominantly HCP form [17] was modified using a set of parameters obtained for a low-cost Ti6Al4V, the research focused on strain rates from 1,000 to $50,000 \mathrm{~s}^{-1}$ [18]. Eq. (5) represents the model E8. The parameters $\alpha_{0}, \beta_{0}$, $\dot{\varepsilon}_{\alpha}$ and $\dot{\varepsilon}_{\beta}$ are the material constants [12]. The meaning and units of the parameters of Eq. (5) are the same than in Eq. (4). This new model does not contain the square root that strains the function, which was eliminated due to it and provides a fair fitting in the determination of strain. Thereby, this model represents the HCP form.

$\sigma=C_{0}+C_{1} \varepsilon^{-\beta_{0}\left[1-\frac{\ln \dot{\varepsilon}}{\ln \dot{\varepsilon}_{\beta}}\right]}+C_{2} e^{-\alpha_{0}\left[1-\frac{\ln \dot{\varepsilon}}{\ln \dot{\varepsilon_{\alpha}}}\right] T} \varepsilon_{r}\left(1-e^{-\frac{\varepsilon}{\varepsilon_{r}}}\right)$.

\section{EXPERIMENTAL AND SIMULATION 2-D PROCEDURE}

The workpieces of Ti6A14V and inserts of tungsten carbide ( $\mathrm{WC} / \mathrm{Co}$ ) have been used in experimental and simulated tests. Insert CNMA432 geometry is defined by a clearance angle $5^{\circ}$, nose radius $0.78 \mathrm{~mm}$ and hone radius $0.0295 \mathrm{~mm}$.

The cutting conditions are the following, cutting speed $\left(v_{c}\right) 120 \mathrm{~m} / \mathrm{min}$, width of cut $(d)$ $2.54 \mathrm{~mm}$, feed rate $(f) 0.35 \mathrm{~mm} / \mathrm{rev}$ and tool rake angle $(\gamma)+15^{\circ}$. Experimental tests have been conducted in a $\mathrm{CNC}$ lathe, with bars of titanium alloy, a diameter of $48 \mathrm{~mm}$ and turning along 4 $\mathrm{mm}$, with and without coolant. The cutting fluid is a conventional emulsion coolant with water at $7 \%$. The forces have been calculated by means of piezoelectric dynamometer, Kistler type 9257B, a multi-channel charge amplifier Kistler type 5070A and DasyLab software. The temperature is measured by an IR pyrometer Optris on the rake face. Thus, cutting forces and temperatures are monitored during the process. TesaVisio 300 optical measurement system allows taking data from chip geometry (the peak tooth height $-h_{\max }$, the valley tooth height $-h_{\min }$ and the tooth width - $W$, indicated in Fig. 1) and from chip thickness after cutting and underformed chip thickness, parameters required to know the chip compression ratio $\left(R_{c}\right)$, and the chip deformation $(\varepsilon)$. Tests were executed with and without the coolant. Each test was repeated three times and an Analysis of Variance (ANOVA) was done to assure the measurement quality, through StatgraphicsPlus software. Thus, ANOVA analysis enables an insight into whether there are significant differences between the means of the variables in the F-test when $P$-values are lower than 0.05 at $95 \%$ confidence level. The experimental data, related to the turning of $4 \mathrm{~mm}$, allowed carrying out a significance study. Fig. 1 exposes the length of experimental chip analysed in order to this study.
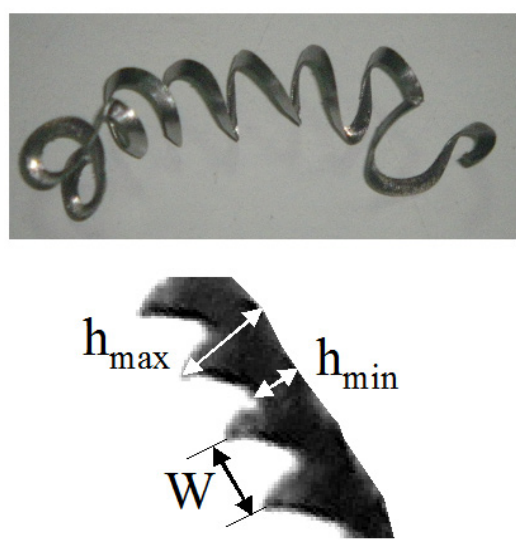

Fig. 1. Experimental chips and geometric parameters

The FE software DEFORMTM uses an Updated-Lagrangian implicit code to simulate the 2-D orthogonal cutting model. The model is a thermo-mechanical simulation with a plastic workpiece (5,000 elements) and a rigid tool (4,000 elements). The cutting tool is considered a rigid body because the effect of using an elastic tool is minimal on the predictions of cutting forces, temperature, and chip formation. In order to investigate the behavior of the segmentation 
process, the mesh in the shear zone must be extremely refined to simulate with sufficient accuracy, the related local deformation and the shear band formation. The shear band region concentrates very high gradients of temperature and shear velocities and they cannot be calculated using wide meshes in this zone. Remeshing algorithms based on the "interference depth" technique were employed, beginning when the tool penetrates the workpiece up to a critical value. This value was selected after previous testing [1], to be a $20 \%$ of the smallest element edge length existing in the mesh (see Fig. 2).

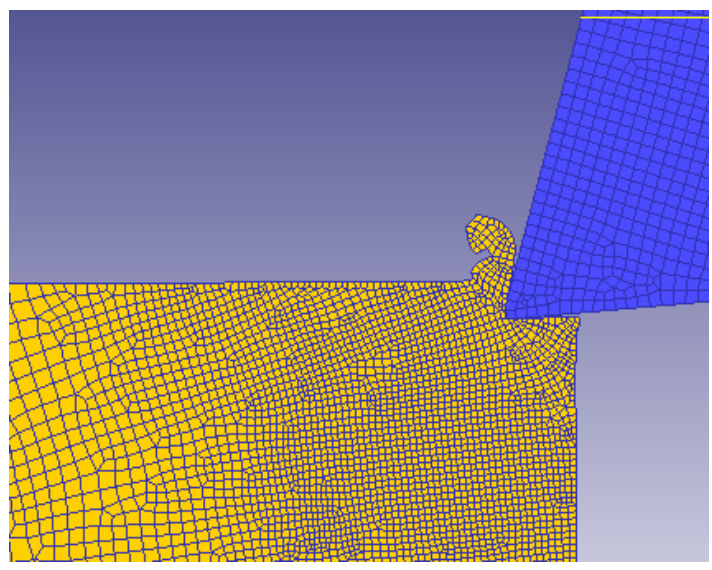

Fig. 2. Mesh/Remesh refining in the shear zone

The influences of the large plastic deformations and the high heat generation that take place during the metal machining process have to be considered when modelling the machining process. The modelling of friction and fracture become important issues in the prediction of the effect of tensile stress on the chip segmentation during orthogonal cutting. Cockroft-Latham fracture criterion [19] is employed to predict the effect of tensile stress on the chip segmentation process. This law is shown in Eq. (6), where $\varepsilon_{R}$ is the fracture strain, $\sigma_{1}$ and $\sigma_{e q}$ are the maximum principal and the equivalent stresses while $D_{c r}$ is a material constant known as normalized critical damage value. The crack is generated according to $D_{c r}$ for the Cockroft-Latham equation [4]. In line with previous research work [3], $D_{c r}$ is fixed in 0.1 in all the simulations in order to make comparisons.

$$
\int_{0}^{\varepsilon_{R}} \frac{\sigma_{1}}{\sigma_{e q}} d \varepsilon_{e q}=D_{c r}
$$

The friction model based on the constant shear hypothesis, derived from the Tresca law, $\tau=m \cdot \tau_{0}$, has been implemented. $\tau$ is the shear stress, $m$ the friction factor and $\tau_{0}$ the shear yield stress. The cutting forces, temperature and chip morphology can be well predicted with an appropriate setting of the friction coefficient, and these predictions are independent of which friction law has been defined in the simulation software, and only the coefficients used have an influence on the results [1]. The friction factor $m$ fixes a constant relation between $\tau$ and $\tau_{0}$, but it has not a physical meaning. Its value conditions the frictional stress on rake face. It is ranged between 0.4 to 0.8 to evaluate different results. The selection of the accurate value of $m$ will be conditioned by the best results of the simulations, according to an iterative procedure conditioned by the mesh, the cutting forces and the temperature on rake face during the simulation [7].

\section{EXPERIMENTAL AND SIMULATION RESULTS}

To analyse the orthogonal cutting model, the predicted and experimentally measured chip morphology, cutting force and temperature were evaluated and their differences discussed.

Table 3. Results from ANOVA Analysis

\begin{tabular}{cccc} 
& $\begin{array}{c}\text { Sum of } \\
\text { squares }\end{array}$ & $F$-ratio & $P$-value \\
\hline$h_{\max }$ & 375656 & 2.94 & 0.06 \\
\hline$W$ & 273598 & 2.37 & 0.10 \\
\hline$h_{\min }$ & 169289 & 2.59 & 0.08 \\
\hline$R_{c}$ & 14442.1 & 2.07 & 0.13 \\
\hline$\varepsilon$ & 16985.5 & 1.54 & 0.22 \\
\hline$F_{c}$ (dry) & 148331 & 2.32 & 0.10 \\
\hline$F_{c}$ (lubricant) & 149725 & 0.68 & 0.51 \\
\hline$T$ (dry) & 5456240 & 0.51 & 0.60 \\
\hline$T$ (lubricant) & 3617570 & 0.00 & 0.99 \\
\hline & & &
\end{tabular}




\subsection{Chip Morphology}

The predicted chip morphology is studied considering the values of the segmented chip geometry $\left(h_{\max }, W, h_{\min }\right)$ defined in Fig. 1 and also taking into account $R_{c}$ and $\varepsilon$ values. The experimental and simulated data are shown in Fig. 3. Moreover, the experimental data obtained are coherent with the literature [6] using similar cutting conditions. The simulated serrated chip segments show relevant geometric similarities and reasonable dimensional attributes. Segmentation frequencies can achieve a wide range in hard machining [3], with values 5882, 2288, 5465, $5714,2100,3846,4755$ and $4366 \mathrm{~Hz}$ in each model. Fig. 4 shows the chip morphology results of the simulations using eight different constitutive models for $m=0.6$. As Özel et al. [5] showed, the chip geometry in FE depends on model equation but it is not affected by the friction coefficient; this behavior can be seen in Fig. 5 . The geometric attributes are coherent with the experimental results, except E5 model results, which present deviations higher than $60 \%$, and a segmented chip is not very clear. The results shown using different friction coefficients are not representative (see Fig. 5). The experimental results $\left(h_{\max }=421 \mu \mathrm{m}, W=411 \mu \mathrm{m}, h_{\min }=205\right.$ $\mu \mathrm{m}$ and chip thickness $=0.451 \mathrm{~mm}$ ) are similar in machining with and without the coolant in order of $\mu \mathrm{m}$. The ANOVA analysis shows that there are no relevant differences between the means of the parameters because $P$-values are $0.06,0.1$ and 0.08 for $h_{\max }, W$ and $h_{\min }$, respectively. The same occurs for $\varepsilon$ and $R_{c}$ (see Table 3). E2 J-C material model and E6 show similar behavior with lower deviation than $13 \%$. E1 and E4 J-C models and $\mathbf{E} 7$ and $\mathbf{E 8}$ also show a corresponding performance, but they have deviations next to $20 \%$ in any case (E1 and E8) and next to $30 \%$ for E4. The worst adjustment to the ratio $R_{c}$ and the chip deformation is achieved by $\mathbf{E} 5$ model, again, while the $\mathbf{E 6}$ and $\mathbf{E} 7$ models offer very low deviations from experimental results. E5 model has a different behavior with a lower frequency of chip formation, so this material law seems to be inadequate for describing the behavior of Ti6Al4V accurately.

\subsection{Cutting Forces}

The outcome comparison of the simulated cutting forces using the eight constitutive models and the three different friction coefficients

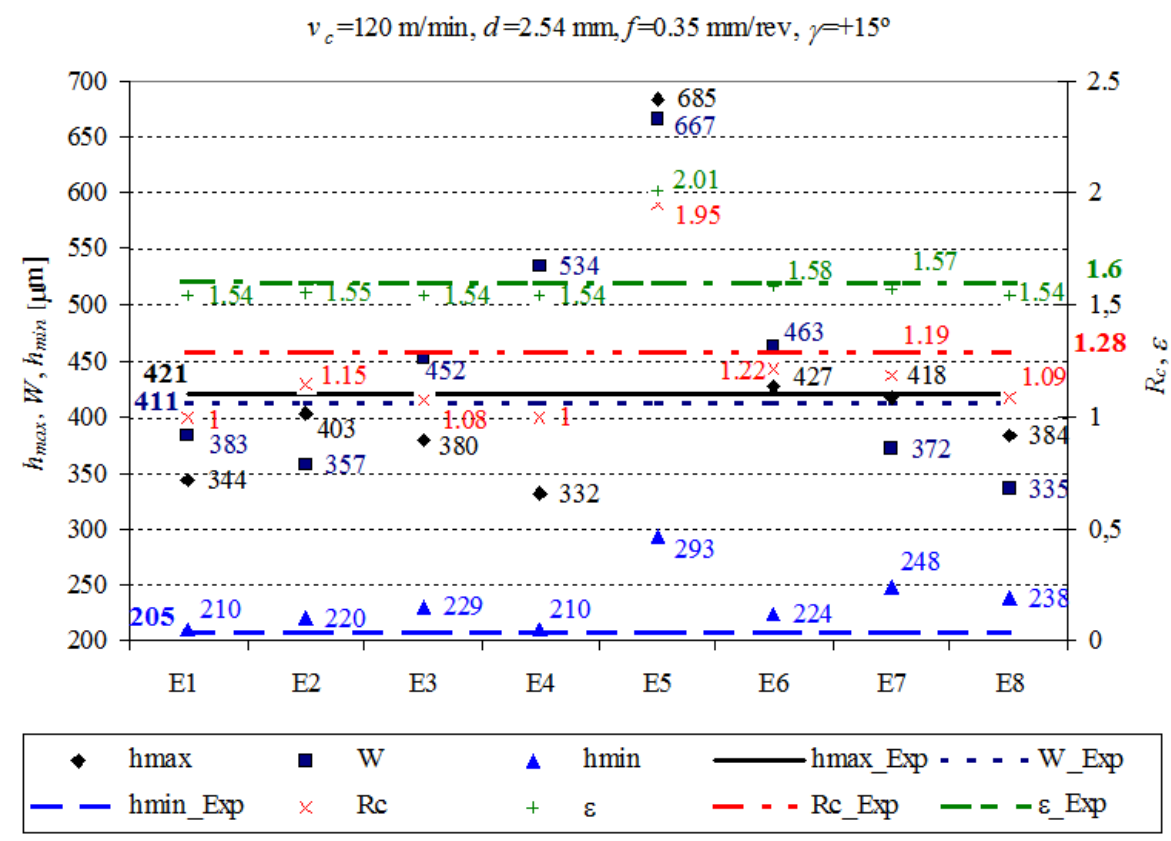

Fig. 3. Experimental and simulated results for serrated chip morphologies 

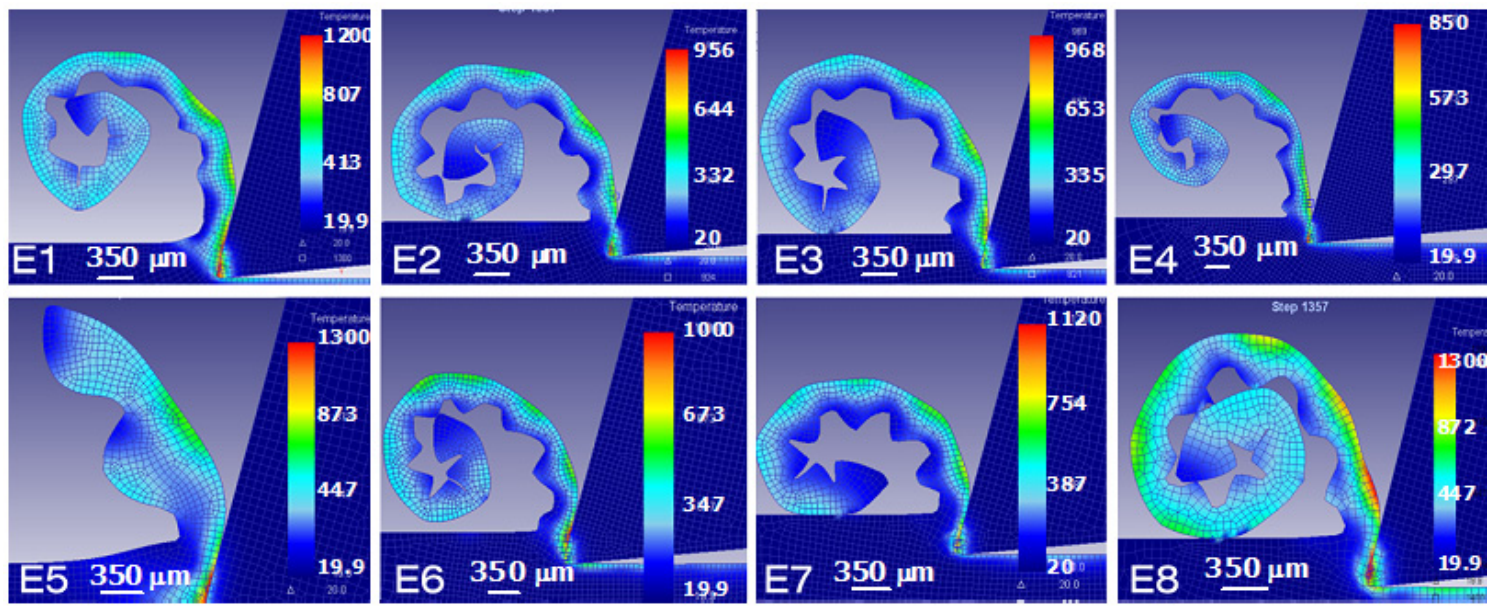

Fig. 4. Saw-toothed chips in eight models for $m=0.6$

with experimental results, with and without the coolant is shown in Fig. 6. The experimental data obtained are $678.5 \mathrm{~N}$ for dry turning and $702 \mathrm{~N}$ for machining with coolant. In both cases, a previous ANOVA analysis provides a $P$-value of 0.1 (dry) and 0.51 (flooded); this is higher than 0.05 , therefore there is no relevant difference between the three measurements (see Table 3). It is clear that the cutting force is higher when the coolant is used; however the thrust force is lower in this case.
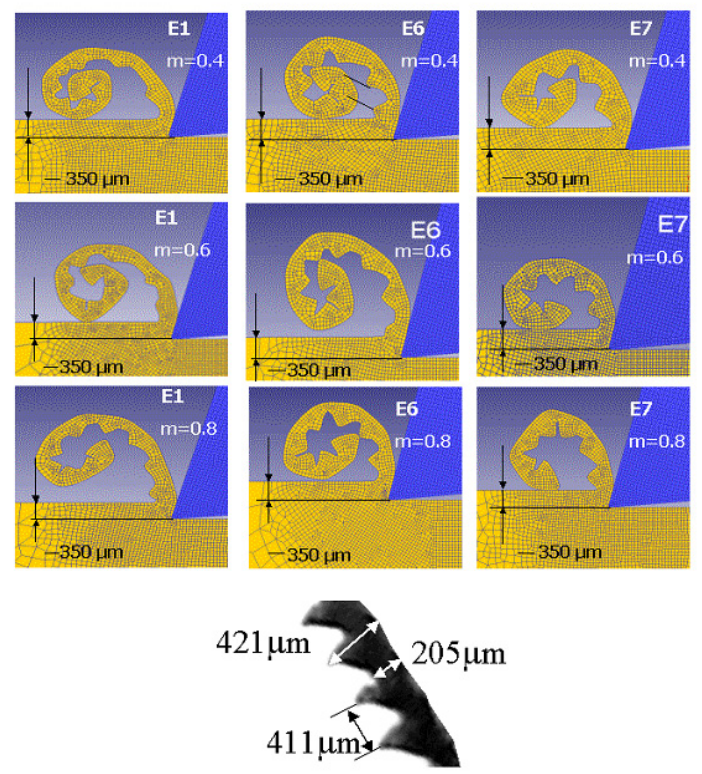

Fig. 5. Different simulation results for serrated chip morphologies
This phenomenon is common in other materials [1]. Globally, the model $\mathbf{E 4}$ gives lower forces than others, and the model $\mathbf{E 8}$ achieves higher forces, independently of the friction value, being both models, the upper and the lower bound respectively. This behavior is explained by the lower flow stress than model $\mathbf{E} 4$ results, which are always very low even if the friction coefficient is increased. Close to $\mathbf{E 8}$ model, it is the $\mathbf{E 5}$ model and next to E4, the E2 and E3 models, these two latter models show similar results. E1 J-C model and E6 and E7 Zerilli-Armstrong constitutive models are more successful and close to experimental data. Especially E6 and $\mathbf{E} 7$ even with the highest friction coefficient $(m=0.8)$, for dry cutting, E6 achieved a deviation of $-1.71 \%$ and with lubricant of $1.69 \%$; besides $\mathbf{E} 7$ obtained a difference of $2.14 \%$ and $-1.28 \%$ for dry and with lubricant machining. Also, there is a good fitting in $\mathbf{E} 1$ model for $m=0.4$ with deviations of $2.4 \%$ and $0.9 \%$ in machining without and with coolant respectively. Using $m=0.6$ the E1 model predictions are lower than $4 \%$ and $7 \%$, but $\mathbf{E 6}$ and E7 also predict on acceptable manner. The results for E5 and E8 constitutive models predicted cutting forces are always higher than others as their strain hardening effect is more observable. As it can be seen, the friction factor has a strong influence on the results; a rise in $m$ supposes an increase of cutting forces because the frictional stress on the rake face is higher. Its value depends on constitutive equations and their parameters and 
its election is conditioned by the experimental results.

\subsection{Temperature Distribution}

Fig. 7 shows the differences between experimental and simulation results in temperature fields measured on the rake face. As expected, the temperatures are higher increasing the friction coefficient value $m$. The highest temperatures were always found in $\mathbf{E 4}, \mathbf{E 5}$ and $\mathbf{E 8}$ models, even when low friction values are used. The lowest temperatures were found in $\mathbf{E 2}$ and $\mathbf{E 3}$ models (see Fig. 4 for $m=0.6$ ) and in addition to the highest deviation (see Fig. 7), which is probably due to stronger deformation produced, which increases the heat and causes higher temperatures. Nevertheless, the temperature distribution pattern is similar for all the material constitutive models used. Experimental data give a temperature value of $866^{\circ} \mathrm{C}$ and $740{ }^{\circ} \mathrm{C}$ without and with the coolant, respectively.

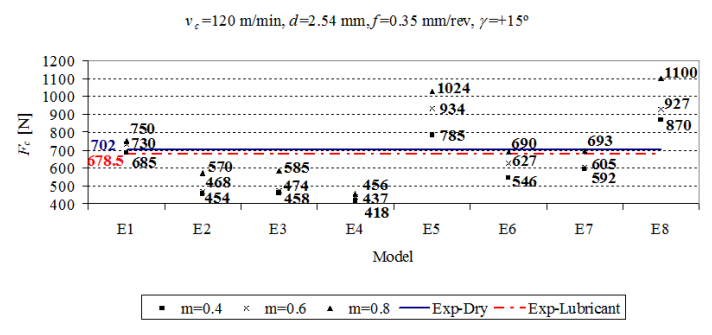

Fig. 6. Experimental and simulated cutting forces

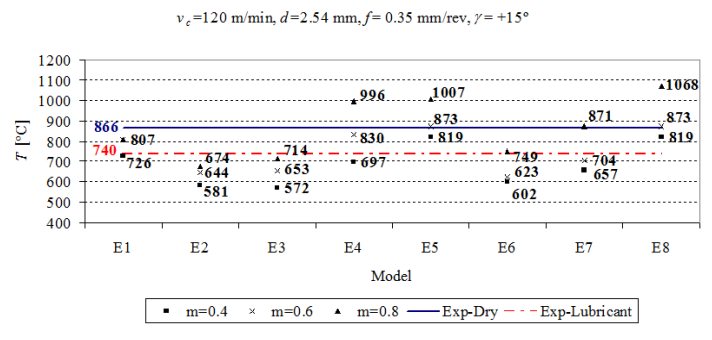

Fig. 7. Experimental and simulated temperatures

The ANOVA analysis gives a $P$-value of 0.6 (dry) and 0.99 (flooded), thus there is no significant difference between the three measurements (see Table 3). The predictions are influenced by the use of coolant. Thus, E5 $(m=0.6), \mathbf{E} 7(m=0.8)$ and $\mathbf{E 8}(m=0.6)$ model estimations are so close to this reference value in dry machining, with deviations lower than $1 \%$ in the case of flooded machining. The best fitting is achieved with E1 $(m=0.4)$ and E6 $(m$ $=0.8)$ models, with deviations lower than $2 \%$. As it occuered in the cutting forces, a rise in $m$ supposes an increment of temperatures, although the temperature is more sensitive than the forces.

\section{DISCUSSION}

Table 4 shows the best global adjustment and deviations found from literature. These latter comparisons are limited because some authors do not report experimental results or there are only graphic presentations of the outcomes. In this study, during the orthogonal cutting, the sawtoothed chip is achieved, which is a very important variable for the prediction of process behavior. Thus, the integration of the FE model and fracture criterion has been favourable in all models, except E5. A possible explanation could be the thermal softening. The high temperatures provoke a lower thermal conductivity and the segmentation frequency $(2,100 \mathrm{~Hz})$ is not sufficient. The four $\mathrm{J}-\mathrm{C}$ models have achieved good results regarding to the chip morphology; although $\mathbf{E} 1$ prediction is the best adjustment, and the differences between experimental and simulated $h_{\min }$ and $F_{c}$ represent percentages lower than any other published [4]; moreover there is a very good prediction of temperatures, which is very important as FE model is a thermo-mechanical simulation (see Figs. 6 and 7), in particular in flooded machining using friction coefficient of $m=0.4$. The other variables, such as $h_{\max }, W, R_{c}$ and $\varepsilon$ achieve acceptable deviations according to other results from literature (see Table 4). In this way, the fitting of the FE model could be considered as adequate.

The Zerilli-Armstrong models provide interesting results. It is seen that E6 and E7 Zerilli-Armstrong models for BCC and HCP crystal structure have a similar behavior (approximately same forces and temperatures), while the modification of Zerilli-Armstrong (E8) is not close to that behavior and has a significant increment of cutting force and temperature. In fact, the simulated results agree with the expected behavior of the HCP structure. It was expected 
Table 4. Deviations in models with best adjustment and from literature

\begin{tabular}{|c|c|c|c|c|c|c|}
\hline & E1 & E6 & E7 & [3] & {$[4]$} & [6] \\
\hline$h_{\max }$ & $-18.2 \%$ & $1.4 \%$ & $-0.7 \%$ & $\begin{array}{c}3.44 \% \\
\text { (J-C Dry) }\end{array}$ & $\begin{array}{l}\text { E1: }-9.6 \% \\
\text { E2: }-13 \% \\
\text { E3: }-29.1 \%\end{array}$ & - \\
\hline$W$ & $-6.8 \%$ & $12.6 \%$ & $-9.4 \%$ & $\begin{array}{c}2.56 \% \\
\text { (J-C Dry) }\end{array}$ & $\begin{array}{l}\text { E1: } 6.4 \% \\
\text { E2: } 72.6 \% \\
\text { E3: } 42.1 \%\end{array}$ & $\begin{array}{c}51.7 \% \\
\text { (J-C Dry) }\end{array}$ \\
\hline$h_{\min }$ & $2.4 \%$ & $9.2 \%$ & $20.9 \%$ & $\begin{array}{c}16.9 \% \\
\text { (J-C Dry) }\end{array}$ & $\begin{array}{l}\text { E1: }-6.5 \% \\
\text { E2: } 26.1 \% \\
\text { E3: } 137 \%\end{array}$ & - \\
\hline$R_{c}$ & $21.8 \%$ & $4.7 \%$ & $7 \%$ & - & $\begin{array}{l}\text { E1: }-9.9 \% \\
\text { E2: }-13.2 \% \\
\text { E3: }-29.3 \%\end{array}$ & - \\
\hline$\varepsilon$ & $4 \%$ & $1.4 \%$ & $1.7 \%$ & - & - & \\
\hline$F_{c}$ & $\begin{array}{c}0.9 \% \\
(m=0.4 \text { Coolant })\end{array}$ & $\begin{array}{c}1.7 \% \\
(m=0.8 \text { Coolant })\end{array}$ & $\begin{array}{c}-1.3 \% \\
(m=0.8 \text { Dry })\end{array}$ & $\begin{array}{c}-11 \% \\
\text { (J-C Dry) }\end{array}$ & $\begin{array}{l}\text { E1: } 7.7 \% \\
\text { E2: }-7.5 \% \\
\text { E3:-8.9\% }\end{array}$ & $\begin{array}{c}10 \% \\
\text { (J-C Dry) }\end{array}$ \\
\hline$T$ & $\begin{array}{c}-1.8 \% \\
(m=0.4 \text { Coolant })\end{array}$ & $\begin{array}{c}1.2 \% \\
(m=0.8 \text { Coolant })\end{array}$ & $\begin{array}{c}0.6 \% \\
(m=0.8 \text { Dry })\end{array}$ & - & - & - \\
\hline
\end{tabular}

to be harder and more difficult to machine than the BCC beta phase. However, E6 model has presented the best adjustment to chip morphology in each case (see Fig. 3). The reason could be that the high temperatures required in $\mathbf{E 8}$ provoke a reduction of thermal conductivity that increases the cutting forces needed to remove material during machining, although it does not affect to chip morphology. Finally, the model E6 for $m=$ 0.8 has demonstrated the best fitting to cutting forces and temperature with coolant and E7 allows a very good approach in dry machining, with deviation of less than $2 \%$, and good results of chip deformation (1.4\% and $1.7 \%$ for E6 and E7 respectively) and chip compression ratio (4.7\% and $7 \%$ for $\mathbf{E 6}$ and $\mathbf{E} 7$ respectively), as it can be appreciated in Table 4. Only $W$ for $\mathbf{E} \mathbf{6}$ and $h_{\text {min }}$ for E7 show some limitations, but not different from the deviations found in the literature (see Table 4). The experimental verification with and without the coolant has demonstrated the influence of the lubrication on the results in cutting forces and temperature.

\section{CONCLUSIONS}

The application of the different constitutive models has proved a strong influence on the results. The model based on Von Mises (E5) flow stress was not capable of predicting the chip shape and forces; although the temperature is predicted for dry machining and $m=0.6$. However, the other models predict the chip geometry with a reasonable accuracy, thus the integration modelfracture criterion is acceptable. The four J-C models have achieved good outcomes regarding the chip morphology, forces and temperature, but the best prediction was obtained with $\mathbf{E} 1$ for $m=0.4$, which differs between experimental and simulated cutting forces, temperature, $h_{\min }$ and $F_{c}$ represent percentages lower than the literature, and it has shown a adequate prediction of temperatures. This last one is relevant for the thermo-mechanical simulations. The $\mathbf{E} 4$ model, with a lower thermal softening coefficient, has not improved the results. Zerilli-Armstrong model, with BCC (E6) and HCP (E7) structures, has achieved the best fitting in flooded and dry orthogonal cutting respectively, for a friction model of $m=0.8$, getting for cutting force, temperatures, peak tooth height and chip deformation, deviation lower than $2 \%$. These 
results represent a stonger fitting than other models studied previously. The HCP modified model has not given good results mainly in the cutting forces; thereby the mathematical modificaton that affects the strain function does not seem adequate in orthogonal cutting.

The cutting force and temperature are affected by friction parameter and lubrication, but the chip morphology is not sensitive to them. Also the models are sensitive to the friction factor, finding that the different values of $m$, that provide the stronger fitting, vary on function of material constitutive equations and constants values. The comparison with the literature indicates that these simulations allow obtaining, by Zerilli-Armstrong models based on the crystal structure of titanium, lower deviations respect to experimental results. Thus, an important contribution has been the assessment of these models. Future works could focus on the exploration of Zerilli-Armstrong models, in particular to find an influence of insert geometry and power consumption during the machining process.

\section{ACKNOWLEDGMENTS}

This work has received financial support from the MICINN (Spanish Government), by means of the project DPI2008-06771-C04-02.

The authors would like to thank the reviewers for their suggestions.

\section{REFERENCES}

[1] Álvarez, R. (2009). Analysis of cutting simplified model, by the finite element method, in light alloys of aerospace interest. Doctoral Thesis;, UNED, Madrid. (in Spanish)

[2] Bäker, M. (2003). An investigation of the chip segmentation process using finite elements. Technische Mechanik, vol. 23, no. 1, p. 1-9.

[3] Calamaz, M., Coupard, D., Girot, F. (2008). A new material model for 2D numerical simulation of serrated chip formation when machining titanium alloy Ti-6Al-4V. International Journal of Machine Tools and Manufacture, vol. 48, no. 3-4, p. 275-288.

[4] Umbrello, D. (2008). Finite element simulation of conventional and high speed machining of Ti6Al4V alloy. Journal of
Materials Processing Technology, vol. 196, p. 79-87.

[5] Özel, T., Yildiz, S., Ciurana, J. (2009). Influence of material models on serrated chip formation in simulation of machining Ti-6Al$4 \mathrm{~V}$ titanium alloy. $12^{\text {th }}$ CIRP Proceedings of Conference on Modelling of Machining Operations, p. 123-131.

[6] Li, R., Shih, A.J. (2006). Finite element modelling of $3 \mathrm{D}$ turning of titanium. International Journal of Advanced Manufacturing Technology, vol. 29, no. 3-4, p. 253-261.

[7] Álvarez, R., Domingo, R., Sebastián, M., (2010). Procedure for the definition of input parameters for a three-dimensional finite element model for Ti6Al4V orthogonal cutting. Proceedings of CIRP$2^{\text {nd }}$ International Conference on Process Machine Interactions, p. 10.

[8] Özel, T., Karpat, Y. (2007). Identification of constitutive material model parameters for high-strain rate metal cutting conditions using evolutionary computational algorithms. Materials and Manufacturing Processes, vol. 22, no. 5, p. 659-667.

[9] Balažic, D.M., Kopač, J. (2010). Machining of Titanium Alloy Ti-6Al-4V for biomedical applications. Strojniški vestnik - Journal of Mechanical Engineering, vol. 56, no. 3, p. 1-5.

[10] Johnson, G.R., Cook, W.H. (1983). A constitutive model and data for metals subjected to large strains, high strain rates and high temperatures. Proceedings of the $7^{\text {th }}$ Symposium on Ballistics, p. 541-547.

[11] Lee, W.S., Lin, C.F. (1998). High-temperature deformation behaviour of Ti6Al4V alloy evaluated by high strain-rate compression tests. Journal of Materials Processing Technology, vol. 75, no. 1, p. 127-136.

[12] Meyer, H., Kleponis, D. (2001). Modelling the high strain rate behaviour of titanium undergoing ballistic impact and penetration. International Journal of Impact Engineering, vol. 26, no. 1, p. 509-521.

[13] Dumitrescu, M., Elbestawi, M., El-Wardany, T. (2002). Mist coolant applications in high speed machining of advanced materials metal 
cutting and high speed machining. Kluwer Academic/Plenum Publishers, p. 329-339.

[14] Johnson, G.R. (1985). Strength and fracture characteristics of a titanium alloy $(.06 \mathrm{Al}$, $.04 \mathrm{~V}$ ) subjected to various strains, strain rates, temperatures and pressures. NSWC TR, p. 86-144.

[15] El-Magd, E., Treppmann, C. (2001). Analysis of strain rate on flow curves for higher temperatures. Zeitschrift fur Metallkunde, vol. 92, p. 888-893. (in German)

[16]Zerilli, F.J., Armstrong, R.W. (1987). Dislocation-mechanics based constitutive relations for material dynamics calculations. Journal of Applied Physics, vol. 61, no. 5, p. 1816-1825.
[17]Zerilli, F.J., Armstrong, R.W. (1996). Constitutive relations for titanium and Ti-6Al4V. Proceedings of the American Physical Society Topical Group on Shock Compression of Condensed Matter Conference, vol. 370, p. 315-318.

[18]Meyer, H. (2006). A modified ZerilliArmstrong constitutive model describing the strength and localizing behaviour of Ti-6Al$4 V$. Army Research Laboratory. Aberdeen Proving Ground, MD 21005-5069 ARLCR-0578.

[19]Cockroft, M.G., Latham, D.J. (1968). Ductility and workability of metals. Journal of the Institute of Metals, vol. 96, no. 2, p. 3339. 